\title{
LA LUCHA POR EL CAPITAL Y LA LUCHA POR LA SUBSISTENCIA. La violencia del sistema capitalista en los indígenas wichí del Chaco argentino
}

\author{
Javier RODRÍGUEZ MIR \\ Universidad Autónoma de Madrid \\ javier.rodriguez@uam.es
}

THE STRUgGLE FOR THE CAPITAL AND THE STRUgGLE FOR THE SUBSISTENCE. The violence of the capitalist system in the natives wichí of the Argentine Chaco

Resumen: El artículo analiza la introducción del sistema capitalista en el Chaco y el alcance de los impactos negativos que tuvo, y aún tiene, hacia sus habitantes originarios. El trabajo focaliza la relación que mantienen las sociedades con la naturaleza y coloca el interés en las tensiones que genera el ingreso del sistema capitalista en la región del Chaco. El artículo analiza los modos en que opera el capitalismo y las formas de subsistencia indígena. Finalmente se expone unas reflexiones críticas sobre el sistema capitalista a partir de la etnografía de los indígenas del Chaco.

Abstract: The article discusses the introduction of the capitalist system in the Chaco and the extent of the negative impacts that had, and still has, towards their original inhabitants. The work focuses on the relation that the societies maintain with the nature and this paper places interest in the tensions generated by the income of the capitalist system in the region. The article analyzes the ways in which capitalism and forms of indigenous subsistence operate. Finally some critical reflections on the capitalist system from the ethnography of the indigenous of the Chaco are exposed.

Palabras clave: Capitalismo. Indígenas. Wichí. Chaco. Depredación

Capitalism. Indigenous. Predation 


\section{La naturaleza del capital y la cultura de la subsistencia}

Partimos de que la naturaleza y el paisaje del Chaco fueron, y son construidos por procesos dinámicos, sociales e históricos con lo cual es importante superar la concepción dicotómica entre "naturaleza" y "sociedad" como entidades separadas, estáticas e inmutables. Es cierto que desde Occidente existe una fuerte tendencia a separar el ámbito de la "naturaleza" del espacio de la "cultura", pero como bien señala Gordillo (2010: 61) hacia 1844 Karl Marx ya señalaba de forma precisa la interacción entre estos dos ámbitos. Al decir de Marx, los seres humanos se apropian de la naturaleza a través de su trabajo y de esta manera producen a la naturaleza y se producen a sí mismos. Si nos atenemos a este punto de vista asumimos que la naturaleza no es independiente, ni anterior, a las formaciones socio-históricas que interactúan en la geografía.

Occidente ha desarrollado un concepto de cultura opuesto a la naturaleza y esta concepción se ha agravado con el desarrollo de la ciencia que busca conocer la naturaleza para dominarla, colocando al hombre y la cultura en una posición de superioridad, fuera del ámbito de la naturaleza (Colombres, 2008: 59). En la actualidad muchos antropólogos coinciden en afirmar que las concepciones de la naturaleza son construidas socialmente y varían con las determinaciones históricas y culturales. Los estudios etnográficos mostraron que la dicotomía naturaleza/ cultura resulta una herramienta inadecuada para dar cuenta de las sociedades con las que trabajaban (Descola y Pálsson, 2001: 101). Este dualismo favoreció la emergencia de otras oposiciones como natural/ sobrenatural que son categorías empleadas con frecuencia para intentar dar cuenta de la cosmología de las sociedades indígenas.

Desde la etnografía amazónica, Viveiros de Castro (2004) nos recuerda que la distinción entre naturaleza y cultura no puede ser empleada para describir dominios o cosmologías no occidentales. Como bien señala el autor, desde occidente los dominios "naturaleza" y "cultura" emergen asociadas a categorías dicotómicas tales como universal/particular, objetivo/subjetivo, físico/moral, dado/construido, inmanencia/trascendencia, cuerpo/espíritu, animalidad/ humanidad, etc. Tal dicotomía también implica una unidad de la naturaleza y una multiplicidad de las culturas. Los análisis de Viveiros de Castro le llevan a afirmar que en las sociedades amerindias la concepción es justamente la inversa, supone una unidad de espíritus y una diversidad de cuerpos, esto es, una multiplicidad de naturalezas y una cultura universal. Esto es que si en Occidente se habla de multiculturalismo, en las sociedades amazónicas de habla de multinaturalismo. En suma, el trabajo de Viveiros de Castro en los grupos amazónicos nos conduce a cuestionar el paradigma occidental de "naturaleza" y "cultura" como una perspectiva presente en todas las sociedades.

En el sistema capitalista, la acumulación incesante del capital condujo a una mercantilización de los procesos sociales en la esfera económica. En este sentido, la acumulación de capital se asocia a la producción así como a la disponibilidad y coste de la mano de obra. En palabras de Colombres (2008: 67) "no es mucho lo que puede hacer el capitalismo para salvar el medio ambiente, pues su canibalismo intrínseco lo lleva a destruirlo, a acumular capital a sus expensas". Es precisamente sobre la base la acumulación de capital que se ha clasificado al trabajo en productivo e improductivo. El trabajo improductivo se trata de una actividad de subsistencia que no produce excedentes, como los sistemas indígenas (Wallerstein, 2012). Por lo tanto, desde la lógica capitalista se trata de transformar los sistemas improductivos en sistemas rentables. No obstante, también hay que señalar que en la región del Chaco, los sistemas "improductivos" le han sido muy funcionales al sistema capitalista. De este modo, cuando el sistema capitalista necesito mano de obra temporal, el resto del año esa misma mano de obra se mantuvo gracias a los sistemas denominados "improductivos", ya sean los propios sistemas nativos o bien en las misiones religiosas. La mano de obra se mantenía en estos sistemas "alternativos" hasta que eran nuevamente requeridos para 
incorporarse como mano de obra en el sistema capitalista. Por tanto, en el caso del Chaco es posible hablar de sistemas subalternos de subsistencia que fueron utilizados por el capitalismo para servirse de la mano de obra de bajo coste y permanecer en la región con el fin de generar excedentes. Recordemos que a mayor remuneración de los trabajadores menos excedentes se generan. Siguiendo a Wallerstein (2012: 32-33) notamos que es precisamente el hecho de conseguir materia prima y fundamentalmente mano de obra económica lo que ha motivado la expansión del sistema capitalista. Las tensiones y conflictos sociales entre los acumuladores de capital y los sectores oprimidos de la sociedad han adoptado formas de luchas sociales, étnicas y culturales.

En la lucha por el capital y la lucha por la subsistencia un elemento clave es la atroz destrucción que se está produciendo sobre el medioambiente. Y en este sentido cabe hablar de un racismo ambiental ya que los efectos y la presión de la destrucción ambiental recae especialmente sobre los sectores más desfavorecidos y marginados de la sociedad. Por lo tanto, ya no sólo nos situamos ante un racismo que Wallerstein (2012: 64) lo asocia a una jerarquización de la fuerza del trabajo y a una distribución desigual de las recompensas. Estamos ante un racismo ambiental capitalista que destruye el medioambiente, es decir, los territorios étnicos, que son la fuente de vida sus habitantes, se trata de un ataque directo y certero al corazón de los pueblos indígenas (Rodríguez Mir, 2011 y 2012).

El sistema capitalista es un sistema de confrontaciones, entre empresarios, entre sectores económicos, entre estados, entre estados y clases sociales, etc., por lo tanto no sorprende que en el Chaco se produzca un incesante conflicto entre la lucha por el capital y la lucha por la subsistencia. Los conflictos y tensiones en el Chaco son constantes, especialmente entre los pueblos indígenas y las empresas capitalistas. Los intereses de éstos últimos suelen coincidir con los objetivos de las políticas gubernamentales. De hecho, no se podría explicar la desertificación, la deforestación y el avance de la frontera agrícola en el Chaco argentino sin la autorización de los gobiernos provinciales y nacionales. Los indígenas se han organizado para afrontar la invasión del sistema capitalista en los territorios étnicos con sus consecuencias devastadoras para el medioambiente y las poblaciones originarias.

\section{La construcción del Chaco}

El Gran Chaco constituye una planicie de aproximadamente $600.000 \mathrm{~km} 2 \mathrm{y}$ abarca parte de Argentina, Bolivia y Paraguay. La región del Chaco fue conocida como "El Impenetrable" y se erigió en un área de refugio de las poblaciones indígenas en donde los españoles muy poco pudieron avanzar en esta área. Las características de las poblaciones indígenas del Chaco asociadas a la alta movilidad, grupos reducidos y escasa estratificación social sumada a la configuración del paisaje (clima, monte, vegetación, etc.) dificultaron que los colonizadores dominaran a las poblaciones nativas. La alta movilidad de las sociedades originarias del Chaco les posibilitó una mayor resistencia durante el período de la explotación colonial europea ${ }^{1}$.

Esta situación persistió hasta la época de la formación de los estados nacionales. Semejante panorama se extendió hasta los años de la independencia en Argentina donde prácticamente la mitad de la geografía del país estaba en manos indígenas puesto que a la región del Chaco debemos sumar la zona sur dominada por los grupos mapuches. La incorporación de

\footnotetext{
1 Es interesante analizar la movilidad de los grupos wichí como un modo de resistencia a la propiedad individual, a la posesión y a la acumulación de bienes propios de la sociedad nacional. Una perspectiva que tampoco debería dejarse de lado, especialmente en las sociedades wichí, es la vinculación entre la movilidad y el conflicto social. Las sociedades wichí presentan niveles de conflictividad y violencia a medida que el grupo crece demográficamente. La movilidad y el desplazamiento grupal fue, y sigue siendo aún, una forma efectiva de resolver conflictos. A pesar de que la sedentarización obstaculizó los procesos de fractura social aún es posible observar entre los wichí resolución de disputas mediante desplazamientos grupales.
} 
estas regiones al estado argentino estuvo marcada por el terror, la violencia y el desplazamiento de tropas militares, tanto al sur como al Chaco.

El Gran Chaco fue habitado principalmente por sociedades cazadoras-recolectoras y en menor medida por algunos grupos que practicaron una agricultura incipiente. Todos los grupos chaqueños se sustentaron sin degradar el medioambiente y han vivido por cientos de años en ese entorno. Sin dudas, la historia socio ecológica del Chaco demuestra que los factores determinantes de la degradación ecológica se asocian con los modos en que los grupos humanos establecen su relación con los recursos naturales.

Los grupos originarios del Chaco subsistieron durante siglos sin agotar el medioambiente hasta que la presencia de los estados nacionales y el ingreso del sistema capitalista basado en los intereses del mercado internacional terminaron por degradar el entorno. Este proceso de invasión capitalista inauguró una etapa caracterizada por los grandes problemas ecológicos que sufre hoy el Chaco y una consecuencia directa fue el desplazamiento por medio de la violencia de las sociedades nativas hacia los lugares más recónditos e improductivos de la región.

La degradación ambiental es producto de los modos en que las sociedades se relacionan con su medioambiente. Este hecho se percibe al observar la subsistencia de las bandas chaqueñas que se basaba en un régimen abierto y un consumo limitado a las necesidades diarias en contraste con las economías capitalistas que se caracterizan por la acumulación máxima de bienes, el consumo ilimitado y la utilización indiscriminada de recursos y materias primas que conllevan inevitablemente a la degradación ambiental.

La relación que mantienen las sociedades indígenas con su entorno es construida y modificada en Occidente de acuerdo a los diferentes intereses y contextos. De este modo, en un primer momento la imagen que se estableció fue la del nativo que era incapaz de manejar su medioambiente y que ponía en peligro el entorno. La imagen del indígena, como un niño, al que se debía ayudar y coincide con proyectos paternalistas e intereses capitalistas en la región. Esta imagen justificaba las intervenciones para "proteger" la "naturaleza", a la vez que abrían la puerta a las industrias extractivas y otras empresas. A partir de los ochenta, mediante alianzas estratégicas entre las comunidades indígenas y grupos ambientalistas, el tema comienza a visibilizarse en la prensa mundial. La amazonia como pulmón del mundo está sufriendo graves procesos de degradación y la imagen que se construye es la del indígena como guardián de la naturaleza, en cierto sentido se trata de un retorno al "buen salvaje". Por lo tanto, la imagen cambiante del indígena en Occidente también impacta sobre las propias comunidades indígenas, que en muchos casos es de utilidad a los intereses nativos con lo cual pueden perfectamente manejar este imaginario y presentarse como los "verdaderos cuidadores de la selva" con el fin de preservar sus propios territorios étnicos.

Los wichí ${ }^{2}$ conforman la cuarta población indígena más numerosa en Argentina (40.036 habitantes), precedida por el pueblo mapuche con 113.680, los kollas con 70.505 y los tobas con 69.452 individuos (INDEC, 2004-2005). Los grupos wichí del Chaco argentino habitan amplias regiones del Gran Chaco y se sitúan fundamentalmente en las riberas de los ríos Pilcomayo y Bermejo.

A lo largo de la etnohistoria wichí es posible observar que estas sociedades debieron adaptarse a drásticos cambios que en ocasiones amenazaron su propia subsistencia. Las sociedades wichí, al igual que todas las sociedades originarias del Chaco, sufrieron fuertes procesos de evangelización que afectó su cosmología, en muchos casos fueron perseguidos de sus propios territorios, debieron cambiar drásticamente sus modos de vida y convertirse en sociedades sedentarias, de practicar la caza, la pesca y la recolección debieron dedicarse

2 Los wichí también se conocen en la literatura etnográfica como "matacos" pero debido a que este término fue empleado tradicionalmente por otros grupos (criollos, pilagás, tobas, etc.) para referirse a ellos de forma despectiva se comenzó a utilizar la palabra "wichí" que recogida de su propio idioma significa "gente". 
a trabajar como mano de obra económica en los ingenios azucareros, en las empresas madereras y en los cultivos de algodón. En definitiva la etnohistoria de los grupos chaqueños en general y de los wichí en particular es una historia de cambios forzosos para adaptarse a las circunstancias y al contexto que les fue impuesto. En la actualidad, las injusticias que sufren estos pueblos sumadas al incumplimiento de sus derechos por parte de los diferentes gobiernos nacionales y provinciales llevaron a los wichí a fundar organizaciones, alianzas y delinear diferentes estrategias con el fin de tener una mayor presencia en la sociedad nacional y así reivindicar sus derechos. La formación de organizaciones, estructuras, alianzas y movilizaciones también implicaron cambios y adaptaciones que no fueron simples. La concreción de organizaciones y alianzas en el caso de las sociedades wichí comportó modificaciones en relación a las identidades, a los modos de percibir las alteridades e implicó adecuaciones a las estructuras jerárquicas de las organizaciones y a sus exigencias jurídicas. En este sentido cabe destacar que los grupos cazadores recolectores del Chaco no presentan estructuras jerárquicas acentuadas con lo cual la conformación de alianzas supuso todo un aprendizaje en cuanto a los modos de organización, en relación a los cumplimientos del ámbito jurídico y en relación a las estrategias y líneas políticas a seguir.

\section{La lucha por la subsistencia: los wichí y su medioambiente}

Como hemos señalado, en las sociedades indígenas no existe una dicotomía entre naturaleza y cultura, sino que la sociedad y el hombre están integrados en un medioambiente y en un territorio que no sólo les posibilita vivir, sino que se convierte en una seña de identidad para el grupo indígena. De lo que se trata es de convivir en armonía con el medioambiente y no dañarlo puesto que cualquier desequilibrio ambiental impactaría de forma negativa en la sociedad. No se trata de que las sociedades originarias sean ecologistas por principio. Debemos atender al papel fundamental que adquiere la cosmología indígena en relación al medioambiente. Sin dudas, la cosmología y el chamanismo regulan y protegen el entorno donde viven. Como bien señala Perrin (1995:9) el papel del chamán es el de restablecer los equilibrios ecológicos, climáticos y a veces sociales con lo cual el chamanismo representa una verdadera institución social. Siguiendo a Calavia (2006: 35) observamos que "tabúes de caza o pesca y restricciones de acceso a determinadas áreas pueden equivaler a una gestión de recursos. A falta de legislación ambientalista, el chamanismo puede ser entendido como un saber regulador de esas relaciones".

También debemos indicar que tanto la agricultura y la ganadería de subsistencia así como otros sistemas de subsistencia como la caza, pesca y recolección no agreden mayormente al medioambiente, y si lo hace, la escala del daño es aún reparable. Sin embargo, el monocultivo, la ganadería extensiva y la extracción a gran escala nos podría conducir a un punto de no retorno. En el caso del Chaco el avance de la frontera agrícola, motivada especialmente por el monocultivo de soja, y la expansión del frente ganadero impacta directamente sobre los territorios étnicos y genera un fuerte proceso de desertificación. Si atendemos a la incompatibilidad ecológica entre la actividad forestal y la ganadera (las especies forestales más valiosas son las más apetecidas por el ganado) volvemos a lo expresado al inicio del artículo de que el sistema capitalista es un sistema de confrontaciones con lo cual entran en competencia la industria forestal con la ganadera por la apropiación de territorios acelerando los procesos de desertificación chaqueña y la invasión sobre los territorios indígenas.

En épocas previas al proceso de sedentarización, las sociedades wichí se organizaban en grupos nómadas de recolectores, pescadores y cazadores. Al igual que la mayoría de las sociedades chaqueñas, los wichí adquirieron un notable conocimiento de su ambiente, en especial de los vegetales y animales.

La división del trabajo por género coloca a la mujer situada en los alrededores más cercanos de la aldea, al cuidado de sus hijos, en la recolección de vegetales y en la preparación 
de alimentos, en búsqueda y transporte de agua y leña, entre otras actividades. Para el hombre se destinan las tareas de caza, pesca y recolección de miel silvestre. En efecto, como la mayoría de las actividades de los indígenas del Chaco, los wichí también dividen las actividades en dos esferas: la femenina encargada de la búsqueda de leña, agua, recolección de frutos, raíces y tubérculos y la masculina responsable de aportar a la economía del hogar insectos, pájaros, huevos y miel y los animales de la caza y la pesca.

El nomadismo de las poblaciones wichí se basaba en circuitos cíclicos que permanecían pautados entre las distintas poblaciones. Braunstein (1992-3) supone que este circuito tenía dos polos, uno marcado por la estación invernal donde el grupo permanecía cerca del río, y otro caracterizado por la estación estival donde el grupo residía en el interior del monte chaqueño. El circuito era recorrido en un solo sentido, haciendo coincidir la estación del año con el lugar propicio con el fin de optimizar los recursos disponibles. Los circuitos comportaban puntos de encuentros sociales con grupos similares en los que seguramente se intercambiaban materiales e información, se pactaban alianzas, se sellaban acuerdos y negociaciones, etc. Las marcadas diferencias entre las estaciones del año supusieron consecuencias en la vida social wichí, interactuando los ritmos naturales con los sociales. Al comenzar las primeras lluvias y durante toda la estación de verano las bandas permanecían en un lugar relativamente fijo. El invierno era una época de carencia alimenticia que obligaba a los grupos a movilizarse en busca de alimentos. Los ritmos estacionales eran también los ritmos sociales de concentración y dispersión (Sterpin 1993, Cordeu y de los Ríos 1982).

La escasez de agua fue uno de los problemas más serios de supervivencia, fundamentalmente en épocas de sequías prolongadas. Normalmente los asentamientos se ubican cerca de determinadas fuentes de agua: ríos, lagunas, lagos y arroyos. Cuando los wichí salían por el monte a zonas alejadas de su aldea llevaban agua en recipientes de calabaza o de cerámica. En la actualidad, la provisión de agua potable continúa siendo un problema en muchos barrios wichí asentados en la periferia de los pueblos.

La pesca es una de las principales actividades de los habitantes de las márgenes del Pilcomayo y del Bermejo. La época de pesca comienza en mayo y continua durante todo el invierno cuando los ríos están bajos y aparecen los grandes cardúmenes. Durante aproximadamente seis meses del año (de abril/mayo a septiembre/octubre) la pesca fluvial sustenta la economía wichí. En las regiones del interior, donde la estación seca es más corta, la producción pesquera es más intensiva y constituye un punto relevante en el ciclo anual. Es un tiempo de bienestar donde se celebran capturas notables y exitosas. La pesca es una tarea esencialmente masculina y se practica en el Chaco con técnicas variadas, la más usual consiste en la utilización de distintos tipos de redes.

Los grupos del Chaco practicaron la caza de forma individual o colectiva y se utilizó al perro de forma auxiliar. La caza colectiva se practicaba durante el invierno con la ayuda de vallas y fuego. Una vez acorraladas las presas se les daba muerte con el arco y la flecha. Con esta técnica se cazaban puercos del monte (pecaríes), jabalíes y corzuelas (cérvidos americanos). Las presas se consumían asadas o hervidas. Los wichí consumían muchas aves, entre ellas la perdiz y varias especies de patos que se atrapaban con un arco provisto de punta roma. La caza del avestruz se realizaba de forma colectiva y para ello se cubrían con armazones cónicos hechos de hojas y ramas.

La recolección de vegetales silvestres se inicia cuando los frutos comienzan a madurar en el mes de noviembre y continúa hasta el mes de enero o febrero. La recolección, a cargo de las mujeres, suele adquirir tanta o más importancia que la caza y la pesca en cuanto a la provisión de recursos para la subsistencia.

La cosmología wichí hace referencia a que numerosas especies de animales y vegetales tienen un "Dueño o Señor" ("le-wúk") que impone normas y/o restricciones a los cazadores, recolectores y pescadores. Estas imposiciones normalmente se refieren a la cantidad de presas que pueden ser capturadas. En el caso de excesos se deberá compensar al "Dueño o 
Señor" por medio de un chamán para que ofrezca al "Dueño" de la especie pieles o armas de caza en compensación por el exceso en el número de piezas capturadas. En caso contrario, el cazador recolector y su grupo se expondrán a graves riesgos y castigos (enfermedades, escasez de presas, etc.). Por lo tanto, como hemos apuntado anteriormente el ámbito de la subsistencia permanece ligado a la cosmología, al chamanismo y a los seres del horizonte mitológico wichí de forma tal que cumplen una función moderadora entre la sociedad y la cantidad de recursos naturales disponibles. También debemos considerar, como sugiere Mashnshnek (1978: 201), que la infracción a sus normas ocasionan graves perjuicios para el desarrollo de las actividades sociales y culturales, con lo cual para el wichí los hechos y entes que, en nuestro modo de percibir la realidad se incluyen en el dominio natural, en las sociedades indígenas se integran en una realidad "cultural". Esto nos reafirma en la idea de que la dicotomía occidental naturaleza/cultura no es posible en muchos casos, especialmente en las sociedades amerindias, aplicarlas de forma directa sin mediar ningún tipo de proceso reflexivo. Por lo tanto, está claro que las sociedades cazadoras recolectoras del Chaco presentan una economía no acumulativa que les permite aprovechar los recursos naturales sin agotarlos.

\section{El territorio étnico}

El tema de la territorialidad se encuentra en el centro de la lucha por el capital y la lucha por la subsistencia. La demarcación y titulación de territorios ancestrales afecta a las propias comunidades originarias, al estado y a las empresas extractivas que mantienen intereses en la región. El concepto de territorio entre los pueblos indígenas tiene un significado diferente al que se le da en Occidente. Asimismo, los modos de explotación y gestión de los recursos naturales difieren mucho. No debemos olvidar que el territorio posee componentes inmateriales de carácter simbólico que deben ser respetados y considerados a la hora de implementar cualquier proyecto. La subsistencia de la comunidad, así como la reproducción y continuidad social, cultural y material del grupo depende de la tierra y sus recursos.

Dicho lo cual se plantea la necesidad de reconsiderar el concepto de "territorio étnico" que no sólo se constituye como un lugar donde "hacer" sino un espacio que posibilita el "ser", esto es, la constitución de la identidad colectiva (Bartolomé 1992). El territorio no solo presupone los recursos económicos y la subsistencia del grupo, también comporta elementos simbólicos y de identidad, la reproducción cultural propia y es un lugar donde reside la memoria colectiva. En este sentido la noción de "territorios equivalentes" para justificar el traslado de poblaciones indígenas desde sus territorios ancestrales hacia otros sitios resulta cuanto menos inapropiada e inadecuada.

La vivencia humana de las comunidades indígenas en América Latina se encuentra muy alejada de las conceptualizaciones propuestas por la geografía económica o la política. Para los estados contemporáneos sus territorios nacionales son concebidos como ámbitos donde desarrollar una hegemonía y un control político sobre los pobladores. Se trata de espacios para ejercer un dominio. Desde el punto de vista economicista la tierra se considera sólo como un medio de producción, al igual que la flora, la fauna, las aguas y los productos del subsuelo que son percibidos como fuentes inagotables. Pero para los habitantes originarios esos mismos espacios tienen diferentes significaciones ya que los espacios vividos son diferentes a los que sólo se conoce o se transita de forma temporal. El lugar del nacimiento y de crianza, los ámbitos de residencia y de trabajo o el lugar donde están enterrados los familiares poseen una fuerte carga emocional derivada de la vinculación afectiva de los seres humanos con su medio circundante. Se trata de un mismo espacio cargado de significaciones que no son necesariamente compartidas por todos los ciudadanos de un Estado, sino básicamente por los que residen en cierta región (Bartolomé, 2010: 17). 
Considerando esta diferencia cualitativa sobre el territorio no sorprende que en la actualidad los movimientos indígenas se movilicen para hacer valer sus derechos y dar a conocer de forma global los modos en que los estados nacionales y las empresas extractivas vulneran sus territorios étnicos. El hecho de luchar por el reconocimiento y titulación colectiva de los territorios étnicos no solo tiene una considerable importancia por sí misma cuando se alcanza este objetivo, sino que estos procesos también alientan a establecer las formas de organización política, favorecen la participación en la sociedad nacional y estimulan los debates sobre las estrategias que se deben implementar. Asimismo ayudan a reinventar el significado del "ser indígena" contribuyendo a la formación de la identidad de los pueblos originarios. En este sentido, comunidades collas y wichí en Argentina fueron capaces de transformar la idea de tierra como un recurso exclusivamente económico hacia la idea de un territorio originario como símbolo de la identidad indígena, y a pesar de que necesitan las tierras para subsistir, supieron sostener sus reclamos y demandas basados en significados culturales más que económicos con lo cual re-significaron de forma positiva la identidad indígena en Argentina (Occhipinti, 2003). En las sociedades indígenas el territorio no se limita al valor económico o la rentabilidad que pueda tener sino que trasciende a ámbitos sociales y culturales más profundos. De este modo, para el caso concreto de las comunidades wichí situadas en Argentina el territorio significa mucho más que una estrategia económica ya que posibilita la reproducción de la propia cultura e identidad mediante la práctica de la pesca, recolección y caza que les permite recrear sus propios modos de vida en relación con los recursos que proporciona la tierra. Y estos modos de vida conforman inexorablemente parte de la identidad social y del ser wichí.

\section{La lucha por el capital}

La colonización española se centró en dominar fundamentalmente a las poblaciones sedentarias con agricultura permanente e intensiva, con alta densidad poblacional, y en algunos casos, con la presencia de mecanismos tributarios propios, con un poder centralizado y con la presencia de diferentes clases sociales. El dominio sobre las sociedades nómadas se obstaculizó por la alta movilidad, por una estratificación social difusa ${ }^{3}$, por la falta de un poder centralizado y por la ausencia de figuras políticas relevantes que sirvieran como interlocutores. Esta situación se trasladará al período republicano.

Como ya hemos hecho mención, hacia fines del siglo XIX el territorio de lo que actualmente constituye la República Argentina tenía consolidada dos fronteras interiores: La Patagonia y El Chaco. El área situada al noroeste de la Argentina (Provincias de Salta, Jujuy y Tucumán), habitadas por grupos indígenas de economía agrícola, colonizadas previamente de forma parcial en la época pre-hispánica, fueron integrados a la sociedad nacional sin mayores dificultades. Sin embargo, en el sur de Argentina y en el Gran Chaco, los colonizadores hispanos encontraron una fuerte resistencia que les permitió a las sociedades indígenas mantener su autonomía hasta finales del siglo XIX y principios del XX. Estas naciones indígenas representaban para el estado argentino la barbarie frente a la civilización de la sociedad nacional. Podemos encontrar dos razones que justificaban el avance y ocupación de estas fronteras interiores. Por un lado, existía una razón de índole económica que propiciaba la incorporación a un sistema mundial y postulaba la urgencia de transformar estos territorios en regiones productivas. Estos temas implicaban la eliminación de las organizaciones

\footnotetext{
3 Las sociedades wichí se caracterizan por una marcada ausencia de connotaciones jerárquicas en el sistema de roles que se corresponde a una concepción igualitaria de los individuos. El jefe del grupo wichí ("kanyat") normalmente es un hombre que tiene autoridad pero no es autoritario. Se encuentra siempre al servicio de toda la sociedad. Su autoridad reside en la palabra y en el convencimiento para adoptar decisiones de forma unánime. Clastres (1978: 27) afirma que la mayoría de las sociedades indígenas de América se distinguen por el sentido de la democracia y el gusto por la igualdad.
} 
económicas indígenas para ser reemplazadas por otras formas de explotación capitalistas. Así las cosas, el debate se centró en los nuevos proyectos económicos y en cómo se deberían llevar a cabo (Lois y Troncoso, 1998). Era fundamental incorporar el estado argentino a un sistema económico mundial y en este marco urgía transformar las denominadas "fronteras interiores" en regiones productivas al servicio de la economía capitalista. Esto implicaba la eliminación o transformación de los modos de producción indígena para alcanzar las formas capitalistas que posibilitaran la inserción de Argentina en el mercado mundial. La construcción del estado argentino se asoció a la creación de un campo de poder donde los capitalistas compitieron por el acceso y los beneficios del poder estatal.

Por otro lado, la construcción del estado nación de Argentina demandaba un proyecto político que implicaba una homogeneización percibida como una necesidad surgida de un proceso de modernización y progreso. Tal homogeneización afectaba a la educación y a la lengua, a la identificación con un territorio único, a la construcción de una memoria nacional que incluyera símbolos, fiestas patrias y próceres compartidos por todos los ciudadanos argentinos. Es en el contexto de este proyecto homogeneizador que se imponía la pregunta que surgía era qué hacer con el indio. De la respuesta emergían dos posturas que obedecían a visiones diferentes del mundo indígena. Una posición se inclinaba por la versión de "un indio víctima" de los tiempos coloniales y del caudillaje que afirmaba que los indígenas podían civilizarse e incorporarse a las tareas productivas del mercado. La otra perspectiva veía en el indio la figura de un criminal sanguinario, en continuo acecho a la sociedad nacional. La solución propuesta era radical, es decir, propiciar el exterminio de todos los indígenas (Quijada, 2000).

Finalmente, el concepto que se fue forjando durante la época fue el llamado "exclusión por fusión" o "por superación numérica". La propuesta consistía en considerar un instrumento fundamental en la construcción de la nación la necesidad de atraer contingentes de inmigrantes europeos. Entre los objetivos emergía la fusión de las poblaciones nativas con los nuevos inmigrantes europeos portadores del progreso y la civilización, para finalmente llegar a conformar poblaciones de "raza blanca y cultura europea" (Quijada, 2000).

El período de construcción de los estados nacionales en América Latina se caracterizó por la necesidad de imponer una homogeneización social y cultural. Este proceso dependerá en las distintas repúblicas latinoamericanas de muchos factores, entre ellos del porcentaje de población indígena, de la capacidad de inserción en el mercado mundial, y de la capacidad y proyectos de la clase gobernante para forjar la nación. En el caso de Argentina, adquirió relevancia la idea del progreso ("civilización y progreso") que se representó en lo urbano y especialmente en Europa. En consecuencia, la clase política argentina generó mecanismos favorables para la inmigración con la intención de atraer inmigrantes europeos para promover la civilización y el progreso en toda la sociedad. Las poblaciones indígenas se convirtieron en el objetivo a civilizar. El proyecto de los gobernantes argentinos civilizaba hacia el interior y confería singularidad e identidad hacia el exterior ya que Argentina emergía en Latinoamérica como un país pionero en implementar este proyecto nacional. En este contexto se hizo necesaria la incorporación de las regiones que aún permanecían bajo dominio indígena (Chaco y Patagonia) al territorio nacional (Rodríguez Mir, 2006).

La necesidad del estado argentino de anexar estos territorios se sumaba a los objetivos económicos del capitalismo que precisaba materias primas y mano de obra. Estos objetivos justificaron la brutal represión contra los indígenas. En este contexto se decidió la ejecución de una ofensiva militar hacia los aborígenes del Chaco, contando con una experiencia previa de las campañas militares hacia la Pampa y Patagonia. El general Julio A. Roca, presidente de la República Argentina entre los años 1880 y 1886, fue el promotor y jefe supremo de las avanzadas militares. La ofensiva militar quedó a cargo del Ministro de Guerra, el General Benjamín Victorica quien hizo avanzar la línea de fortines y con ello logró un asedio y una presión más firme sobre los grupos indígenas del Chaco, especialmente de 
aquellos que habitaban en las riberas del río Pilcomayo (Gordillo y Leguizamón, 2002:25). Los objetivos de esta campaña fueron la eliminación de las últimas fronteras interiores para unificar el territorio nacional y la construcción de una nación moderna, civilizada y homogénea. Por lo tanto, la construcción del actual estado nación argentino está manchada por la sangre derramada por los indígenas, quienes fueron perseguidos, reprimidos, masacrados o desplazados hacia regiones improductivas ${ }^{4}$.

La consecuencia inmediata de las campañas militares fue la apropiación, por el uso de la fuerza y la represión, de las tierras indígenas. Las mismas fueron entregadas a diversas compañías colonizadoras. Las poblaciones indígenas se vieron forzadas a recluirse en zonas apartadas, inhóspitas, inaccesibles e improductivas, o bien a incorporarse al sistema capitalista como mano de obra estacional y de bajo coste. Todo este proceso implicó la desestructuración de los modos de vida indígena y la subsunción de las poblaciones indígenas a la economía de mercado. En la región del Chaco muchas poblaciones indígenas fueron obligadas a trasladarse caminando cientos de kilómetros para trabajar en los ingenios azucareros en un régimen de explotación y terror. En el Chaco se aplicó la coerción física, directa y brutal, esclavizando a las poblaciones nativas, con el fin de controlar la mano de obra. Los castigos corporales, con el látigo y el cepo, para la disciplina laboral generaban terror entre las poblaciones indígenas durante los meses de la plantación en los ingenios azucareros (Isla 2002).

La formación del estado argentino comportó el uso de la violencia para apropiarse de sus territorios, la imposición de una brutal represión para obligarles a incorporarse como mano de obra, y una política estatal que impuso en toda la sociedad nacional un imaginario que suponía que los indígenas habían sido exterminados durante las campañas "civilizatorias" de los militares. A pesar de que la presencia pública de los aborígenes argentinos es cada vez más frecuente, aún persiste en gran parte de la sociedad nacional (y extranjera) la idea de que los indígenas fueron totalmente exterminados y que ya son parte del pasado o bien que por el mestizaje con contingentes europeos se generó una población criolla que desplazó a los nativos (Carrasco 2002).

\section{Terror y violencia en sistemas depredadores}

Los recursos naturales no abundan y no son ilimitados. El sistema capitalista, basado en las premisas de la productividad y rentabilidad invade con mayor frecuencia territorios indígenas para obtener materias primas y mano de obra de bajo coste. Ya nadie se asombra de que sean los países hegemónicos quienes exporten sus industrias contaminantes y empresas extractivas hacia los países más pobres. Siguiendo a Colombres (2008:64) notamos que la presión del sistema capitalista mundial actúa directamente sobre los estados más débiles, quienes autorizan la recepción de empresas no sólo extractivas y contaminantes sino también de residuos tóxicos y otras basuras en sus territorios a cambio de conseguir financiación para paliar la grave situación por la que atraviesan.

El capitalismo conforma un sistema que se fundamenta en el beneficio y la acumulación inacabable de riquezas. En un sistema orientado a la obtención del máximo beneficio sin importar lo que destruye (bosques, montes, ríos, poblaciones...). La rentabilidad y el poder permanecen relacionados: el primero acumula riqueza; el segundo la sustenta con la ley y la fuerza. Esta lógica de acumulación ilimitada no es universal, sólo se sustenta dentro de los

\footnotetext{
4 Esta violencia hacia las sociedades indígenas aún persiste, con las nuevas invasiones de las empresas capitalistas en los territorios étnicos del Chaco, cuando son olvidados por el estado y no se brindan los servicios básicos necesarios como la atención primaria a la salud, especialmente en relación a la tuberculosis, mal de Chagas y desnutrición. A pesar de que la situación de desnutrición indígena en el Chaco es apremiante no se adopta ningún tipo de medidas para paliar tal situación.
} 
engranajes de un sistema que responde a la producción y acumulación infinita de bienes, a costa de una máxima degradación ambiental y de la explotación de las poblaciones nativas.

La distribución de los bienes a nivel mundial es abrumadoramente desigual... casi el 70\% de la población mundial vive con el $3 \%$ de la riqueza y el $10 \%$ de la población concentra el $86 \%$ de la riqueza. La inequidad genera más pobres. En relación a la pobreza y exclusión de los pueblos originarios, especialmente del Chaco, este sistema capitalista depredador ha avanzado sobre los territorios indígenas generando una degradación sin precedentes. Expulsó a comunidades enteras hacia tierras apartadas e improductivas y en muchos casos los utilizó, por medios coercitivos, como mano de obra de bajo coste.

La competencia de los sectores capitalistas por el acceso a los recursos naturales originó frecuentes pugnas con el fin de apropiarse de la mayor cantidad de tierras posibles, que, una vez obtenidas, se sobreexplotaron sistemáticamente. El resultado fue una terrible degradación del entorno (deforestación, desertificación, contaminación, expansión agraria, etc.) que desembocó en la pérdida de los recursos de subsistencia de los grupos originarios del Chaco y en la subsunción de éstas al sistema capitalista. En este contexto y ante la escasez de mano de obra, los aborígenes se vieron obligados a incorporarse al nuevo sistema de trabajo asalariado. La sobreexplotación, la coerción, el sistema de deudas, las malas condiciones laborales etc., fueron estrategias utilizadas por las empresas capitalistas con el fin de abaratar costos y asegurarse la escasa mano de obra. En suma, la alianza estado/ capital trató la cuestión indígena privilegiando los intereses económicos y políticos, ya que desde los primeros colonialistas hasta los últimos capitalistas se caracterizaron por despojar a los habitantes originarios de sus territorios y utilizar su fuerza de trabajo para llevar a cabo actividades que dañaban a los territorios indígenas.

El ingreso de la economía capitalista en el Chaco, a partir del siglo XX, basada en las premisas de acumulación de bienes en pocos individuos, en la propiedad privada, en la distribución parcial y en el acceso restringido de bienes, fue minando y desestructurando las formas de organización social y política de las sociedades indígenas. Todo este proceso desembocó en la actual pauperización de las sociedades originarias del Chaco que sufren enfermedades, pobreza, hambre y discriminación social ante la indiferencia de las políticas públicas.

Pasemos ahora a las víctimas de este violento e inadmisible proceso. Observemos los imaginarios de los sistemas depredadores en la cosmología wichí. En las sociedades wichí la máxima alteridad se establece mediante una oposición radical entre el mundo de los vivos y el mundo de los muertos. En estas sociedades la alteridad cosmológica se caracteriza por tener un gran poder con intenciones malignas hacia la sociedad wichí. Estas características hacen que la alteridad genere peligro y temor en las comunidades wichí. Es por ello que los wichí desarrollan comportamientos cautelosos y parcos en el sentido de que intentan evitar el contacto con la alteridad. La mayoría de las sociedades wichí presentan una configuración social que opera en términos de oposición que posibilita diferenciar perfectamente entre el contexto familiar por un lado y el contexto extraño por otro.

La noción de humanidad (wichí) es central en la sociedad y las formas opuestas a la condición de persona (wichí) permanecen asociadas directamente con el imaginario de la alteridad, y fundamentalmente con unos espíritus denominados "ahot"5. La preservación de la condición de ser humano (wichí) es básico para conservar la paz y la armonía, tanto en el nivel individual como en el social. El universo wichí es ordenado en dos dominios fundamentales: el wichí y el ahot. La condición de persona (wichí) está dada por la asociación entre un cuerpo ("t’isán") y un principio vital ("-hesék"6). El principio vital otorga sentido y

5 "Ahot", denominado también "ahat" en la literatura etnográfica. Esta diferenciación se asocia a la procedencia de los grupos y a las variantes lingüísticas existentes.

6 "Hések" o "husek" de acuerdo a las variantes lingüísticas regionales. 
voluntad al individuo y su ausencia se traduce en comportamientos considerados asociales que exponen al individuo en particular, y al grupo en general, a un peligro potencial ya que el lugar vacante puede ser ocupado por un espíritu indeseable y maligno (ahot). Este desequilibrio puede ser generado a partir de la irrupción de sucesos inesperados, sorpresivos y dolorosos.

El susto y el terror son emociones que pueden causar la separación del cuerpo ( $\mathrm{t}$ 'isán) y del principio vital (hesék) y la persona estará propensa a la ocupación de espíritus depredadores (ahot) que generarán diversas clases de enfermedades. Por tanto, las experiencias que generan el terror entre las poblaciones wichí poseen una significación extra al sufrimiento de la propia experiencia en sí, y es que el pánico y el miedo pueden conducir a la incorporación de espíritus malignos (ahot) perdiendo por completo la voluntad y las intenciones wichí. Este hecho es un punto vital ya que en las sociedades wichí las experiencias asociadas al miedo, violencia y terror afectan y ponen en peligro a la propia humanidad wichí. Las situaciones de violencia y terror no sólo implican el sufrimiento de la misma, sino que expone a las personas a una posible posesión que puede conducir a su muerte y poner en riesgo a todo el grupo.

De acuerdo a los wichí, los ahot provocan enfermedades y pueden causar la muerte. La muerte significa un cambio ontológico en el que de un estado wichí (persona) se pasa a otro estado ahot (espíritu maligno). El fallecido se convertirá en un espíritu extraño y peligroso. Ahora bien, ¿es posible asociar la figura de máxima alteridad (los espíritus dañinos ahot) a las formas violentas y destructivas con que emergió el capitalismo en el Chaco? Evidentemente el sistema capitalista configura para los grupos originarios del Chaco un dominio de absoluta alteridad que se traduce en actitudes de violencia, excesos, acumulación desmedida de poder, etc. Quizás las sociedades wichi hayan incorporado nuevos personaje que puedan aparecer en su cosmología wichí inspirados en el sistema capitalista. Por ejemplo, un personaje cosmológico que he recogido de mi propio trabajo de campo entre grupos indígenas wichí de la Provincia de Formosa (Argentina) es el Wilán. Se trata de un espíritu maligno (ahot) que se presenta bajo forma humana en el monte chaqueño, montado sobre un caballo deslumbrante, con valiosas monturas, luciendo ropa cara y con detalles que muestran su riqueza. Si un wichí se ve sorprendido y le mira a los ojos, el Wilán le causará la muerte instantánea para finalmente devorárselo. Riquezas, monte, muerte y antropofagia, en suma todos estos elementos se encuentran presentes en la invasión del capitalismo en la región chaqueña, especialmente en los territorios étnicos e indígenas.

\section{In(conclusiones)}

Estamos hablando de un capítulo que aún no está cerrado, está inconcluso, en donde los pueblos originarios de Argentina, fueron excluidos, perseguidos, discriminados, y marginados de la sociedad occidental. Sus tierras y recursos les fueron arrebatados, y es hasta el día de hoy que no han recibido ni el reconocimiento suficiente y menos aún una reparación histórica por el agravio y los daños recibidos.

De acuerdo a los datos presentados consideramos pertinente realizar algunas reflexiones sobre el sistema capitalista a partir del estudio de las sociedades wichí. Las investigaciones etnográficas sobre los wichí abren el debate sobre los postulados que se sostienen desde el mercado capitalista moderno. La mayoría de las sociedades denominadas "pre-capitalistas" apuntan a la satisfacción de un conjunto definido de necesidades mientras que en el sistema capitalista el objetivo se centra en la acumulación ilimitada del capital. Se trata de sociedades originarias que producen en la medida de lo que necesitan, pero no más. La lógica de las sociedades wichí se opone a la acumulación, al exceso y al individualismo, todas ellas propiedades de la alteridad (Rodríguez Mir, 2006b). 
En este contexto también se cuestionan los conceptos de escasez emanados del ámbito de la economía de mercado. Para los economistas la escasez surge de la relación entre los deseos ilimitados del ser humano y la limitación para satisfacer dichos deseos. Una persona no puede tener todo lo que desea y por tanto deberá elegir qué deseos cumplir. Las sociedades wichí en tiempos previos a la colonización tuvieron todo lo que necesitaron y desearon pocas cosas. Vivieron adecuadamente sin industria, con una agricultura mínima y con pocas posesiones materiales. En suma, el propio sistema capitalista moderno fue el que generó escasez basado en la creación ilimitada de deseos.

Un aspecto importante en el análisis comparativo entre las sociedades wichí y el sistema capitalista son los diferentes modos de producción. Mientras que las sociedades capitalistas dependen del avance tecnológico y del personal remunerado, en las sociedades wichí la producción depende del conocimiento adquirido sobre las especies de plantas y animales de su entorno y el producto final es distribuido y compartido socialmente mediante mecanismos de reciprocidad generalizada. El conocimiento en estas sociedades es accesible a toda la población.

Otra especulación fue considerar que las sociedades nativas consumían todo su tiempo en las actividades de subsistencia. Sin embargo, las sociedades cazadoras recolectoras del Chaco dispusieron de una gran cantidad de tiempo libre para el ocio que favoreció el desarrollo de una amplia y rica vida social. En el caso de los wichí el tiempo libre se tradujo en numerosas reuniones de carácter festivo. Una gran diferencia entre las sociedades no occidentales y el capitalismo es que en las primeras existe un mayor control del trabajador sobre los materiales, las herramientas y el tiempo. En el capitalismo el trabajador pierde completamente el control sobre los medios de producción, los materiales, las herramientas, el tiempo y los recursos. Los artículos de consumo, y no las personas, dominan el ser social. En consecuencia, las relaciones sociales entre las personas se deshumanizan y se tornan relaciones sociales entre cosas.

En las sociedades wichí adquiere gran importancia la cooperación y la reciprocidad generalizada, la propiedad colectiva de las tierras y de los recursos, el interés no está puesto en la acumulación de bienes sino en la movilidad y adaptabilidad, el acceso de todos los miembros a las fuerzas de producción, mientras que se reserva la propiedad individual al ámbito de las herramientas las cuales son compartidas con facilidad.

Las decisiones en las sociedades wichí son tomadas previo consenso colectivo en el que prima la mejor elección para todo el grupo, a diferencia de la economía de mercado que se caracteriza por decisiones que se toman a nivel individual y que pueden generar una gran contradicción entre el beneficio individual y el social.

En las comunidades wichí, la economía de estos grupos cuestionan seriamente los postulados sostenidos por la teoría económica ya que el régimen de acceso abierto no genera conflictos en las sociedades ni produce sobre-extracción debido al consumo controlado que poseen. Los economistas enfatizaron en los derechos de propiedad como forma de garantizar el uso sostenible de los recursos y lamentablemente derivó en una acumulación máxima mediante el uso indiscriminado de los recursos degradando progresivamente el hábitat. Van Dam (2000) concluye que la degradación del medioambiente depende del tipo de la relación que cada grupo humano establece con la naturaleza.

El proceso colonial y el período de formación del estado argentino confinaron a las sociedades wichí a zonas marginadas y de difícil acceso. La adaptación a las difíciles condiciones impuestas por el medio ambiente fue posible, entre otras cosas, por la baja densidad poblacional de los grupos y por sus habilidades para aprovechar al máximo los recursos disponibles del medio sin llegar a agotarlos. La gran eficacia adaptativa de las sociedades wichí concuerda con los grupos cazadores recolectores en general cuya distribución mundial abarca zonas ampliamente diversas, inhóspitas y remotas cuyo rango varía desde los cálidos desiertos hasta el frío polar. Estos datos indican la presencia en las sociedades caza- 
doras recolectoras de una alta eficacia en todas sus adaptaciones. Probablemente la mayor encrucijada que debieron sufrir los grupos cazadores recolectores del Chaco permanezca asociada al proceso de colonización y al ingreso del capitalismo en la región iniciando un proceso que condujo a la degradación de los recursos naturales vitales para la subsistencia de estas sociedades. El colonialismo y el sistema capitalista impusieron una lógica de dominación y sometimiento que se desarrolló, fundamentalmente, sobre intereses económicos basados en la acumulación y concentración de los recursos naturales en manos de unos pocos individuos e inauguró un proceso irreversible de degradación ambiental que colocó en una situación extremadamente incómoda y de peligro a las sociedades indígenas del Chaco.

La alteridad wichí, tanto en el dominio cosmológico como social, se representa dotada de un gran poder y de una gran capacidad de destrucción y apropiación. Estas características generan actitudes de precaución y sentimientos de temor en los grupos wichí. Probablemente el proceso histórico de violencia y explotación a los que se vieron sometidos los grupos wichí haya acentuado las conductas de este tipo y haya reforzado el imaginario sobre el poder y la peligrosidad de la alteridad. El imaginario de la alteridad wichí coincide con la forma en que las empresas capitalistas se desempeñaron en la región chaqueña: abuso de poder, coacción, ausencia de controles, excesos, ambición ilimitada y utilización de la violencia.

Todas las experiencias de imposición de sistemas hegemónicos y de poder son diferentes pero también conservan experiencias comunes de colonización. La resistencia contra la dominación, explotación y discriminación capitalista está, y seguirá estando presente. La movilización indígena ha hecho ver al mundo que otro mundo es posible, y esa posibilidad está cada vez más cerca.

\section{Bibliografía}

BARTOLOMÉ, Miguel Alberto

1992 "Presas y relocalizaciones de indígenas en América Latina", Alteridades, 2 (4):17-28.

2010 "Interculturalidad y territorialidades confrontadas en América Latina", RUNA XXX(1):929.

BRAUNSTEIN, José

1992-3 Territorio e Historia de los Narradores Matacos, en Hacia una Nueva Carta Étnica del Gran Chaco, vol. V, Las Lomitas, Argentina, pp: 9-74.

CALAVIA SÁEZ, Óscar

2006 "El indio ecológico. Diálogos a través del espejo", Revista de Occidente, 298:27-42.

CARRASCO, Morita

2002 "Una perspectiva sobre los pueblos indígenas en la Argentina". Capítulo 11. Disponible en: http://www.cels.org.ar/common/documentos/informe_2002_cap_11.pdf Acceso: 1208-2015.

CLASTRES, Pierre

1978 La sociedad contra el Estado. España: Monte Ávila Editores.

COLOMBRES, Adolfo

2008 América como civilización emergente. Amagord Ediciones, Madrid.

CORDEU, Edgardo y DE LOS RÍOS, Miguel.

1982 "Un enfoque estructural de las variaciones socioculturales de los Cazadores Recolectores del Gran Chaco", en Suplemento Antropológico, Universidad Católica, Revista del Centro de Estudios Antropológicos, vol. XVII, núm. 1, Asunción, Paraguay.

DESCOLA, Philippe, and Gísli PÁLSSON

$2001 \quad$ Naturaleza y Sociedad. Perspectivas antropológicas. México: Siglo XXI.

GORDILLO, Gastón

2010 "Historias de los bosques que alguna vez fueron pastizales: La producción de la naturaleza en la frontera argentino-paraguaya", Población \& Sociedad 17:59-79.

GORDILLO, Gastón y Juan M. LEGUIZAMÓN

2002 El río y la frontera. Editorial Biblos, Buenos Aires. 
INDEC. Encuesta Complementaria de Pueblos Indígenas (ECPI) del Censo Nacional de Población, Hogares y Viviendas del año 2001. Buenos Aires, 2004-2005. Disponible en:http://www. ISLA, Alejandro indec.gov.ar/micro_sitios/webcenso/ECPI/index_ecpi.asp Acceso: 12-08-2015.

2002 Los usos políticos de la identidad. Indigenismo y Estado. Buenos Aires, Editorial de Las Ciencias.

LOIS, Mariana; TRONCOSO; Claudia.

1998 Integración y desintegración en el Chaco: los debates en la Sociedad Geográfica Argentina (1881-1890). Primer Congreso Virtual de Antropología y Arqueología. Disponible en:http://www.equiponaya.com.ar/congreso/ponencia1-16.htm Acceso: 12-08-2015

MASHNSHNEK, Celia O.

1978 "Aspectos mítico religiosos en la economía de los Mataco del Chaco central (República Argentina)", Revista Española de Antropología Americana:181-202.

OCCHIPINTI, Laurie

2003 "Claiming a Place. Land and Identity in two Communities in Northwestern Argentina", Journal of Latin American Anthropology, 8(3): 155-174.

QUIJADA, Mónica.

2000 Indígena: Violencia, tierras y ciudadanía, en Homogeneidad y nación con un estudio de caso: Argentina, siglo XIX y XX. Quijada, Mónica; C. Bernand y A. Scheneider. CSIC, Madrid.

PERRIN, M.

1995 Lógica Chamánica. Chamanismo en Latinoamérica: Una revisión conceptual. J. Galinier, I. Lagarriga and M. Perrin. México, Plaza y Valdés: 1-20.

RODRÍGUEZ MIR, Javier.

2006 "Resistencia y confrontación en Argentina. Negación y exclusión de los pueblos indígenas". Gazeta de Antropología, 22.

2006b Los Wichí en las fronteras de la civilización. Capitalismo, violencia y shamanismo en el Chaco Argentino. Una aproximación etnográfica. Ecuador, Abya Yala.

2011 Violencia y racismo ambiental en Argentina. Resistencia y movilización de los pueblos indígenas en el Chaco. Etnografía wichí del conflicto, Editorial Académica Española, Alemania.

2012 "Los sinuosos caminos del racismo: El racismo ambiental en Argentina", Revista de Antropología Experimental, 12:43-59.

STERPIN, Adriana.

1993 "La Chasse aux scalps chez les nivaclé du Gran Chaco", en Journal de la Société des Americanistes, LXXIX, París, pp: 33-66.

VAN DAM, Chris.

2000 "Condiciones para un uso sostenible: el caso del chaguar (Bromelia hieronymi) en una comunidad wichí del Chaco Argentino". Revista de desarrollo rural y cooperativismo agrario, núm. 4. Departamento de agricultura y economía agraria. Universidad de Zaragoza, España.

VIVEIROS DE CASTRO, Eduardo

2004 "Perspectivismo e multinaturalismo na América indígena", O que nos faz pensar, 18: 225254.

WALLERSTEIN, Immanuel

2012 El capitalismo histórico. Siglo XXI, España.

\section{$\operatorname{coc}$}

